\title{
CASTING SUPERALLOYS FOR STRUCTURAL APPLICATIONS
}

\author{
Göran Sjöberg \\ Volvo Aero Corporation, Trollhättan, 46181 SWEDEN \\ Keywords: Casting, Structures, Assembly, Welding
}

\begin{abstract}
Open air investment casting of superalloys for aerospace applications is a process that dates back about 80 years. The introduction of vacuum metallurgy 30 years later made the development and the use of higher strength and higher temperature resistant superalloys feasible since the very reactive alloying elements like aluminum, titanium and niobium that brought these propertied could be handled in the casting process without being oxidized.

The development of the high strength weldable Alloy 718 (INCONEL 718 patented by INCO) 50 years ago enabled large size, complex geometry, structural castings to be produced efficiently and thus replacing previous weld assembly part designs made of less potent stainless steel grade alloys. With the introduction of hot isostatic pressing as a post processing step the quality of the castings could be significantly improved allowing for more critical aircraft engine applications.

With increasing diameters there is a diminishing return in terms of capital investment, number of parts and capital amortization and today there is a reversed trend to build the very large diameter structures as assembly parts. Cast and wrought parts may be mixed in such structures for weight optimization. In this context the welding is the ultimately critical process not least when more temperature capable alloys are considered at the same time.
\end{abstract}

\section{Introduction}

To melt metal in a crucible followed by the casting into a mold to bring shape to objects is a process basically as old as metallurgy itself although hammering applied on native materials (on copper e.g.) may be claimed as a more virgin process. The investment casting process which is extensively used today to produce "net shape" structural parts for aircraft engines is in fact essentially the same as the lost wax process used by the Egyptians several thousands of years ago - bringing the desired geometry into a wax pattern - invest the pattern with a soft, moist, malleable clay coat - dry the investment coating out - heat the investment assembly to melt out the wax (lost wax) - further heating of the empty mold to bring strength through the sintering of the clay particles - filling the hot mold with molten metal - freezing the metal and finally breaking away the mold and cutting away the ingots to free the desirable cast metal object.

Although the basic metal shaping idea is the very same there is still a tremendous difference between the simple old process and the much elaborated procedures employed in the vacuum investment casting technology used today to produce the very large complex shaped structures (as large as $2 \mathrm{~m}$ diameter) from very reactive heat resistant materials as titanium or superalloys ${ }^{\mathrm{i}}$. 
The present day investment casting technology covers little less than a hundred years of development and has seen several distinct development steps both relating to the largest size of the castings that could be produced as well as the alloy compositions feasible for the casting process. Most importantly the advent of vacuum metallurgy, little more than half a century ago, made it possible to produce high quality parts from the high temperature capacity alloys where reactive elements as titanium, aluminum and niobium are essential and could be prevented from being oxidized during the melt processing. The introduction of HIP (Hot Isostatic Pressing) as a post-processing step was an important quality improvement by its ability to close internal porosity in the castings.

With time there has been a natural trend of increasing the size of the cast parts but there is today for various reasons a reversed trend of splitting up these very large structures into sections to be joined by welding. This design philosophy introduces a larger flexibility for optimizing the performance of the component.

\section{Before Vacuum Metallurgy}

The revival of the lost wax method as a process (as we today know as the investment casting process) to produce net shape parts for aircraft engines dates back to the pre-jet engine era facing the second world war and specifically to the manufacturing of the turbine blades for the turbochargers enabling high altitude flight with piston engines. As often, coincidences have their role in technological developments and in this prewar instance it was the marriage between an early application of the investment casting process used for dentistry implants in New York and the development needs at close by GE in Schenectady ${ }^{\mathrm{ii}}$. In this coincidence it also happened that it was not any of the experimental heat resistant alloys developed at GE, being investment cast into shape, which came out as the best one during the testing. Instead it was the actual dental implant alloy - Vitallium - developed by Haynes Stellite Co. for Austenal Laboratories (the dental company) that proved most successful for the turbocharger blades after lowering the carbon content and was thus used extensively for such blades in the war time with 35 million produced during those years, figure 1 .

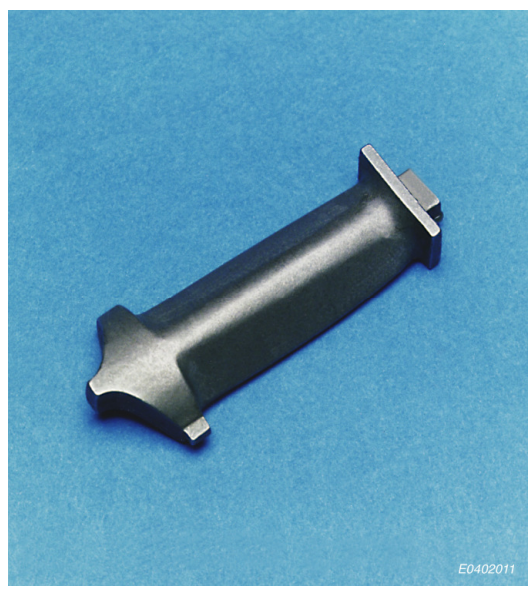

Figure 1. The first successful investment casting - a turbine blade for an aircraft engine turbocharger made of the cobalt base superalloy Vitallium. 35 million were produced during the

Second World War. Courtesy Alcoa Howmet. 
The composition of Vitallium is approximately $60 \%$ cobalt, $20 \%$ chromium and $5 \%$ molybdenum and it is thus a cobalt-base solution strengthened alloy originally developed as a tool material by the Stellite company. Today it would be classified as a cobalt base superalloy since it has considerable strength above those temperatures $\left(>600{ }^{\circ} \mathrm{C}\right)$ where traditional ironbased high alloy stainless steels have lost most of their strength and corrosion resistance. Chromium brings adequate corrosion resistance and the molybdenum improves the high temperature creep properties. Although chromium and molybdenum easily oxidize they are far less reactive than titanium, aluminum and niobium which are essential precipitation hardening elements in the chemical compositions of present day nickel base superalloys.. Vitallium was thus a more feasible alloy for the available open air metallurgical processing.

With the era of jet engine propulsion that was born during the same war time years intensive development work was also carried out to improve the heat resistance of alloys ${ }^{\text {ii }}$ for use in one of the hottest and most highly stressed parts of the engines - the turbine blades - for obvious thermodynamic efficiency reasons. Surprisingly, the basic compositions of the alloys developed during those years were not very different from those that exist today - table 1. Most of this early alloy development work was driven by the need for more efficient military engines with the commercial applications always trailing.

Table 1 - Comparison between selections of WW2 alloys and present day alloys

\begin{tabular}{|l|l|l|l|l|l|l|l|l|l|l|}
\hline Alloys WW2 & Cr & Ni & Co & Fe & Mo & W & Nb+Ta & Al & Ti & C \\
\hline \hline X 40 & 25 & 10 & 55 & & & 7 & & & & 0.5 \\
\hline Vitallium & 27 & 3 & 61 & & & 6 & & & & 0.2 \\
\hline Nimonic 80 & 21 & 74 & & & & & & 0.6 & 2.4 & 0.04 \\
\hline \hline Alloys Today & & & & & & & & & & \\
\hline \hline FSX - 414 & 29 & 10 & 52 & 1 & & 8 & & & & 0.25 \\
\hline Alloy 718 & 18 & Bal. & 1 & 19 & 3 & & 5 & 0.5 & 0.9 & 0.05 \\
\hline Waspaloy & 20 & Bal. & 14 & & 4 & & & 1.3 & 3.0 & 0.08 \\
\hline Alloy 939 & 23 & Bal. & 19 & & & & 2.4 & 1.9 & 3.7 & 0.15 \\
\hline
\end{tabular}

By adding many alloying elements to generate very complex chemical compositions, metallurgical processing problems naturally occur, e.g., the reactions of certain elements as mentioned above. Fundamentally, the intention of all the efforts is to bring higher strength and to preserve that strength at the highest possible temperatures. One adverse side effect of this is that it is difficult to get the desired shape by forging. The alternative for mass production is then casting and this was inherent in the application of the investment casting process of the Vitallium alloy.

The development of an industrially viable vacuum melting metallurgical technology was put into service around 1950 and was probably the most important step for improving the quality of cast as well as of wrought superalloy materials. This vacuum technology also enabled further development of alloys as well as the applications of these alloys for critical aircraft engine components. It should be noted that vacuum metal melting technology on a laboratory scale was available early and also used in the alloy development efforts discussed here.

During the post war years there was a constant tradeoff between wrought and cast processing versus the chemical composition and the properties of the products ${ }^{\mathrm{iii}}$. Basically, all alloys were 
first cast; either into ingots for further processing by forging or rolling into wrought products or used directly as net shaped castings. It is well known that forging, which is plastic work put into a casting, will improve the quality by breaking larger inclusions into smaller ones and by enabling grain refinement through re-crystallization. In some critical applications, such as disks, only wrought alloys were accepted for this reason.

\section{The Vacuum Revolution}

Vacuum Induction Melting (VIM) was a truly revolutionary process in two ways; first by using electromagnetic induction as a heating source for the melting of the metal charge in a ceramic crucible by an electric coil outside the crucible and secondly by performing this under vacuum conditions. By these two measures it was possible to add all desired alloying elements to a melt without interference of an atmosphere of any kind and thus reactive elements could liberally be added without the risk of oxidizing. Hence, very clean ingot could be produced for further processing.

Alloys intended for airfoil applications developed towards compositions for higher heat resistance in many ways. The fact that the grain boundaries grow weaker with temperature also encouraged the development of directional solidification techniques and finally the single crystal blades. In addition internal cooling channels could be incorporated into the castings; all measures to improve engine performance by allowing for higher combustion temperatures.

Vacuum also helped to evaporate deleterious elements with high partial pressure such as sulfur, phosphorus, selenium, lead or antimony. At the same time this evaporation could be enhanced by the magnetic stirring that could be introduced through the induction coil, since fresh metal surfaces could be exposed to the action of the vacuum on the top surface. However, there was also an evaporation toll of some desirable metallic alloying elements with high partial pressures, such as aluminum, for which compensating additions would be needed.

In addition, the vacuum is also beneficial in supporting the metallurgical reaction by which carbon will reduce oxide impurities to form carbon monoxide that can be pumped away. The same metallurgical reaction will also enable a reduction of excessive levels of carbon in the melt.

Also important was the introduction of a subsequent re-melting of the ingots from the VIMprocess. By striking an electric arc between a VIM- ingot, used as an upper electrode, and a lower pool of melt, solidifying in a copper mold, as the bottom electrode the material is drip-wise re-melted under vacuum. This Vacuum Arc Re-melting - the VAR-process - is in fact even more efficient in exposing the molten metal to vacuum than in the VIM-process and so also its refining ability. An alternative process to VAR is the Electro-Slag-Refinement - the ESR- process equally efficient in refining the melt. The VIM-VAR/ESR ingots thus produced provide excellent forging stock material and for critical applications, as for disks, often with an additional VAR process - thus named triple melt material.However, as previously mentioned, alloying contents, especially high $\mathrm{Al}+\mathrm{Ti}$, which renders the superalloys virtually impossible to hot working (e.g. Alloy 939) must be cast into rather small diameter ingot sticks typically 5 inch diameter as stock for small castings - and directly suitable for the re-melting in an investment casting furnace. In fact, melt stock for casting usually only requires VIM and for larger scale castings VIM master melt furnaces are used directly for the melting of the various virgin alloying 
elements as well as recycled (scrap) material to establish the proper chemistry of the alloy. Pouring into the large molds is then directly made from the master melt furnace.

The photo in Figure 2 amply illustrates the main vacuum furnace features necessary for successful investment casting of equiaxed material although a large variety of designs are available to meet different needs. The illustrated equipment is for batch processing suitable for limited production. The furnace illustrated is a two chamber - an upper and a lower - design separated by a vacuum tight sealing lid. Both chambers are easily accessed by the large swing doors. In the upper chamber suitably sized bar stock material is placed in the crucible inside the induction coil as seen incorporated with the upper swing door. Upon closing the door, rapid evacuation will bring chamber pressure down to approximately one millionth of an atmosphere and induction melting can commence without risk of oxidation.

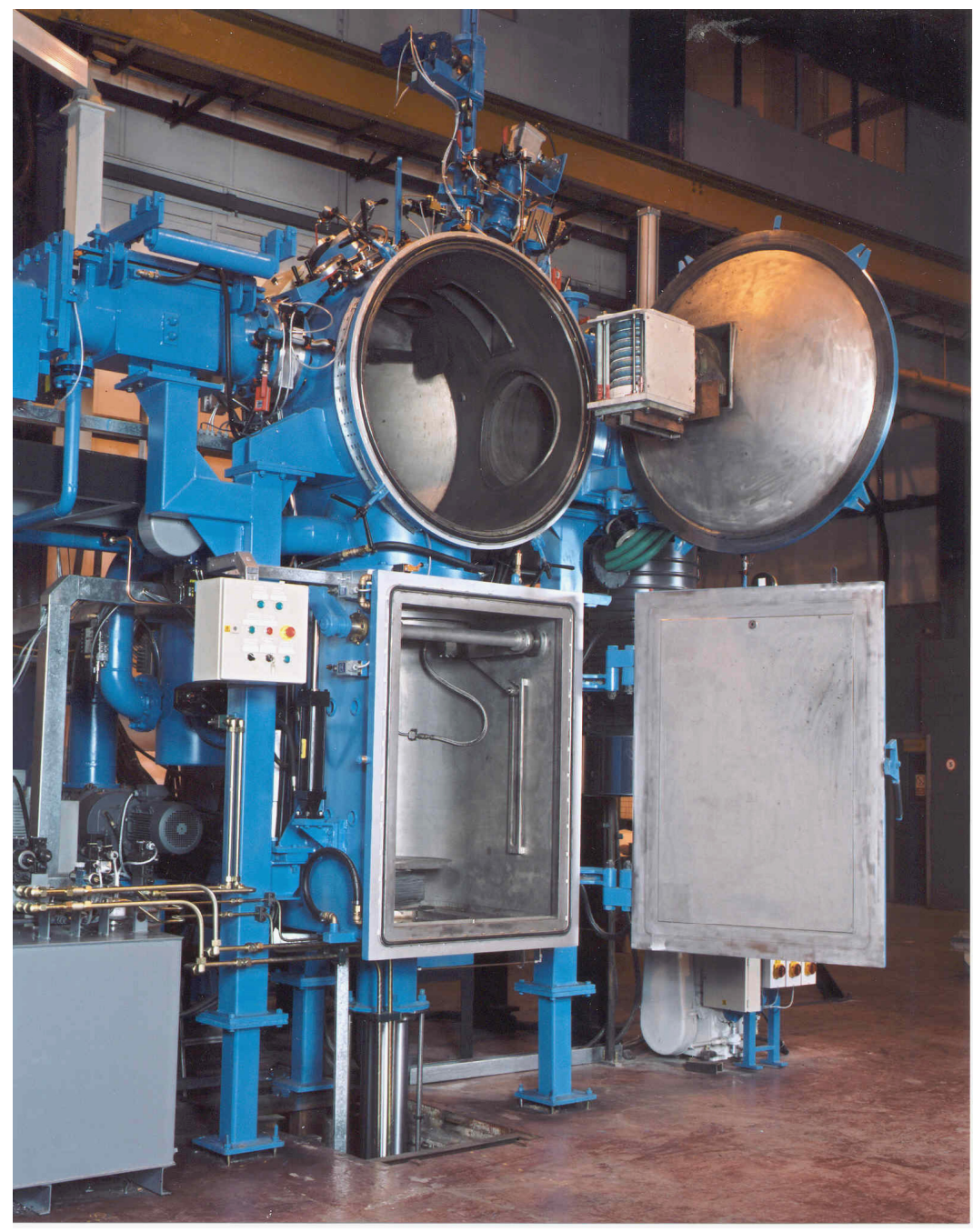

Figure 2. Two chamber batch type vacuum investment casting equipment for equiaxed investment castings. The melting of the feed stock material (usually a piece of a bar) is done in a crucible by the induction coil lining the crucible (visible as attached to the swing door of the top chamber). The lower chamber is in the open position to receive the externally preheated casting molds. Courtesy Consarc. 
The lower chamber is operated independently. The investment casting mold is preheated in a separate furnace and rapidly transferred into the lower vacuum chamber where it is positioned to adequately receive the molten charge after the closure of the door and the appropriate evacuation of the chamber when the connection between the two chambers can be opened for the pouring into the mold.

\section{Large Structures}

Following the success of casting air foils and turbine blades there was an interest in the casting of larger structures for the aircraft engines with other requirements on the alloy compositions and the casting equipment. In this respect the development of the Alloy 718, or INCONEL 718 as it was first known since it was INCO that introduced it, in the late 1950's was a very fortunate event since this alloy married well with the concept of vacuum investment casting of large integral structures which took place a few years later. By 1985 very large structures, like the compressor rear frame for the illustrated in figure 3, with a melt pour weight of many hundred kilos, could be produces as one-piece castings.

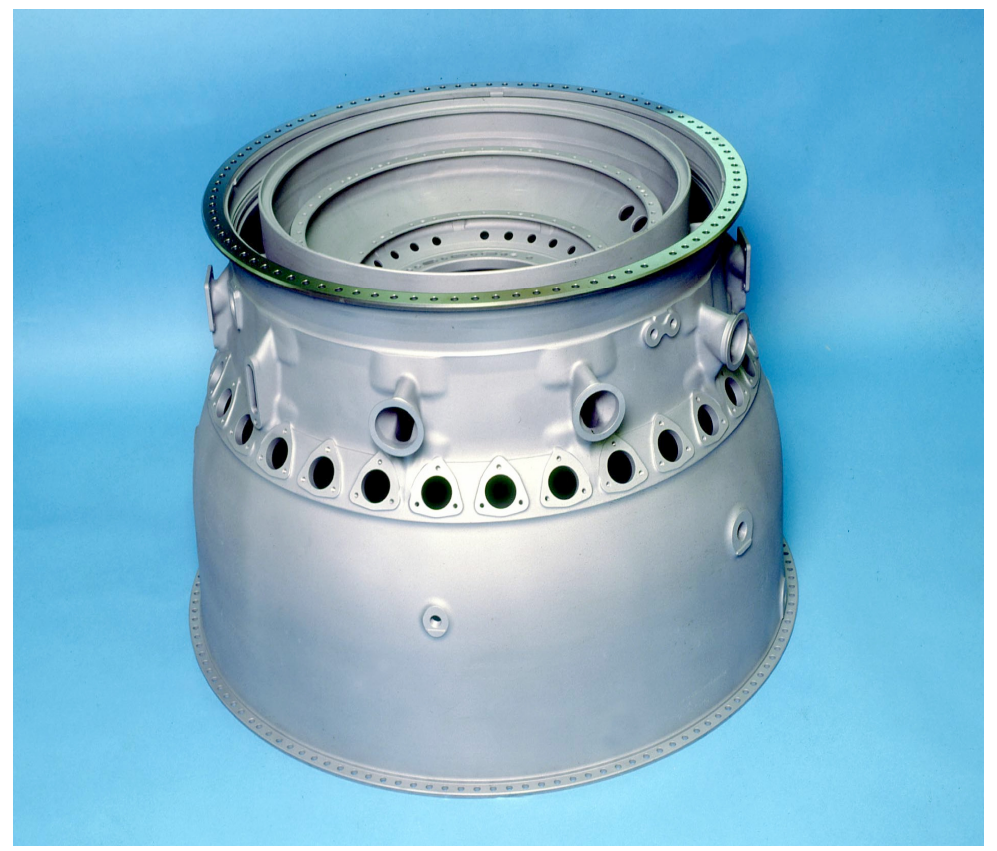

Figure 3. A compressor rear frame (CRF) as an Alloy 718 one-piece casting. Cast on flanges have been replaced for strength with wrought rings and joined by EB-weld to the cast main body. The structure here is shown after final machining.

No superalloy is even near the success of the very high strength Alloy 718 which is primarily due to the fact of its sluggish gamma double prime hardening response. This gives ample time to avoid inadvertent hardening during the cooling and also makes it possible to monitor the hardening behavior by proper later heat treatments. In addition the presence of the delta phase in this alloy makes the grain size control manageable in wrought products. The slow hardening response also makes this alloy the most weldable among the precipitation hardening superalloys. 
Irrespective of all possible care taken during the casting process of large complex structural parts, they are impossible to produce without defects such as local porosity or cracks among many others. The external defects are readily identified by Fluorescent Penetrant Inspection (FPI) and the internal porosity by X-ray inspection. Hot Isostatic Pressing (HIP'ing) was introduced as an effective means of closing internal porosity that does not connect to the surface through the action of argon gas at very high pressures (approximately $1000 \mathrm{~atm}$.) and at very high temperatures (typically $1100^{\circ} \mathrm{C}$ ) for a few hours. Often, the large structural parts in aircraft engines are designed for fatigue life and large size defects will severely reduce this life of the component by early initiation of cracks mainly from thermal stresses. It is thus important that all such defects are found and properly repaired by grinding them out and to restore the geometry by filling with weld deposit material.

Since HIP is a very essential quality improving post processing step it is used on all cast critical aircraft engine parts. For the very largest parts (above $1.8 \mathrm{~m}$ diameter), however, there is today no unit commercially available for such operations. I essence this means that such parts must be split into sections to fit into available equipment and later be joined by welding and for large aircraft engine structures welding turns out to be one of the most important manufacturing methods today.

\section{Alloy Limitations}

It is reasonable that not only the airfoils and turbine blades should be able to meet higher engine temperatures but also that the larger structural parts are following suit. For this reason more temperature capable alloys than Alloy 718 have been evaluated for such applications.

A derivate of Alloy 718 is the alloy René 220 where basically the niobium of Alloy 718 is replaced with tantalum. Since these two alloying elements are very close chemically, the two alloys are metallurgically very close, although René 220 will sustain $50{ }^{\circ} \mathrm{C}$ higher temperature than Alloy 718. In the CRF, illustrated in Figure 4, cast René 220, was used to meet higher temperature requirements in the complex core part joined with a ring rolled wrought Alloy 718 aft part skirt by a circumferential EB-weld.

Waspaloy is another choice among existing alloys for castings with an approximately $100^{\circ} \mathrm{C}$ higher endurance limit of $750^{\circ} \mathrm{C}$ versus $650^{\circ} \mathrm{C}$ for Alloy 718 . However, Waspaloy has considerably lower yield strength and the low cycle fatigue properties will suffer accordingly. Among the gamma prime hardening alloys Waspaloy is a rather lean alloy in terms of the precipitation hardening elements $\mathrm{Al}$ and $\mathrm{Ti}$ and the corresponding amount of hardening phase. Although being a rapidly hardening gamma prime alloy it is still, with some difficulties, weldable due to the lower strength. 


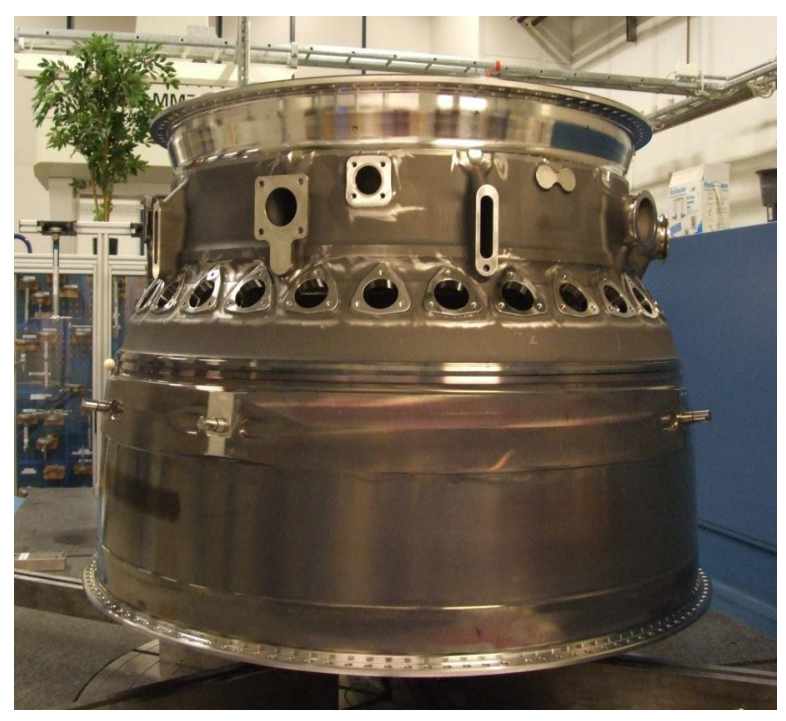

Figure 4. A René 220 casting (upper complex geometry CRF part) joined by EB-welding to a wrought alloy 718 skirt.

Casting of this type of alloys that contain significant amounts of $\mathrm{Al}$ and $\mathrm{Ti}$ as well as some Mn (for castability) can be more complicated than may be first anticipated ${ }^{\text {iv }}$. When melting an alloy of this kind in the upper vacuum chamber of a furnace type as shown in Figure 2 Mn will evaporate from the melt (due to its high partial vapor pressure). The accumulated Mn vapor in the upper chamber will reach the preheated mold in the lower chamber as soon as the connection between the chambers is opened and will there react with the remaining air entrapped in the micro-porosity of the mold to form $\mathrm{MnO}$ on the mold surface. When the melt is then poured into the mold the $\mathrm{Al}$ of the melt will react with the $\mathrm{MnO}$ due to its much higher affinity to oxygen and will form $\mathrm{Al}_{2} \mathrm{O}_{3}$. This latter oxide will agglomerate and finally show up as numerous defects on the casting in need weld repair.

Other gamma prime hardening alloys with higher content of $\mathrm{Al}$ and $\mathrm{Ti}$ are even more temperature capable and tempting for designers than Waspaloy and several development efforts to use them for structures have been reported. Specifically the very potent airfoil alloy 939 which can be used at $850{ }^{\circ} \mathrm{C}$ has been evaluated ${ }^{\mathrm{v}, \mathrm{vi}}$ not least within the European MMFSC and CLEAN development programs, Figure5. The strong interest among designers for the 939 alloy is not only because of the temperature capacity but also due to the very high strength by the high content of gamma prime hardening elements $\mathrm{Al}$ and $\mathrm{Ti}$ (table 1).

Alloy 939 hardens fast (contrary to Alloy 718) and is unyielding and therefore cracking is easily induced by the thermal stresses involved in the casting process. All large cast structures will need significant weld repair and alloy 939 is certainly no exception and could be considered more prone to cracking than other alloys of lower strength. It is one of the least weldable alloys but repair is still feasible but with considerable precautions to improve the possibility to alleviate the stresses produced by the welding. 


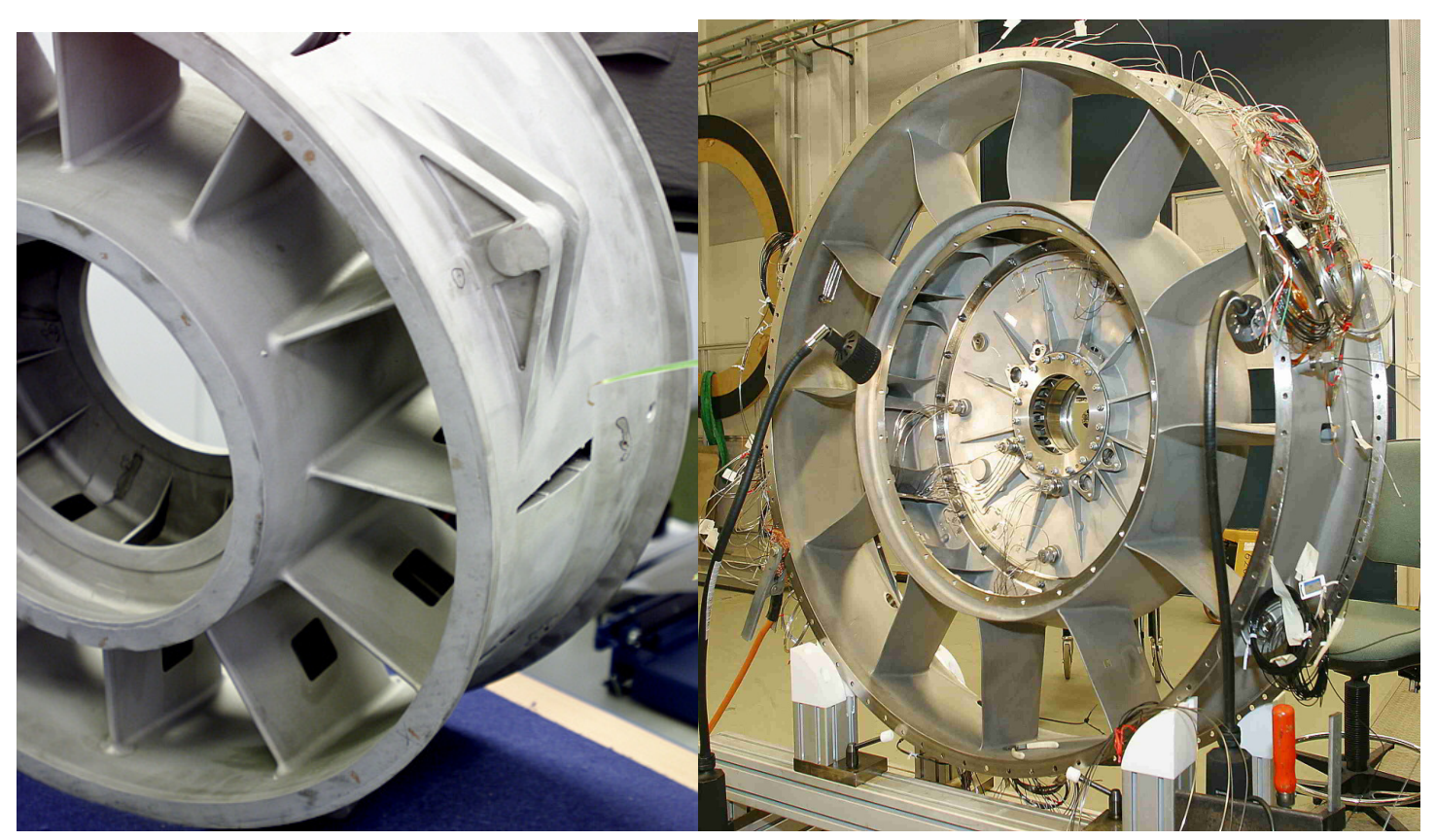

Figure 5. Two complimentary European R\&D program for evaluation of Alloy 939 for structures. The MFFSC program with a general evaluation of the alloy for castings (left) and the CLEAN program with an actual tested engine design of a cast turbine exhaust case (the bolted on hub is an Alloy 718 casting).

First the alloy has to heat treated into the softest possible condition which for this kind of alloy is the overaged condition where the hardening gamma prime phase precipitates is in the coarsest possible condition when the precipitates confer least strength to the material. Secondly a filler material must be used which is soft in comparison as C 263 or the new Haynes 282 alloy. Such a successful repair is indicated in Figure 6. However, from a design point of view it may be argued with justification that if a repair in such a highly stressed fillet location (where cracks during the casting also tend to appear) is made with a soft filler material the LCF-life will be considerably impaired and the part itself could as well be cast from the filler material used with better success.

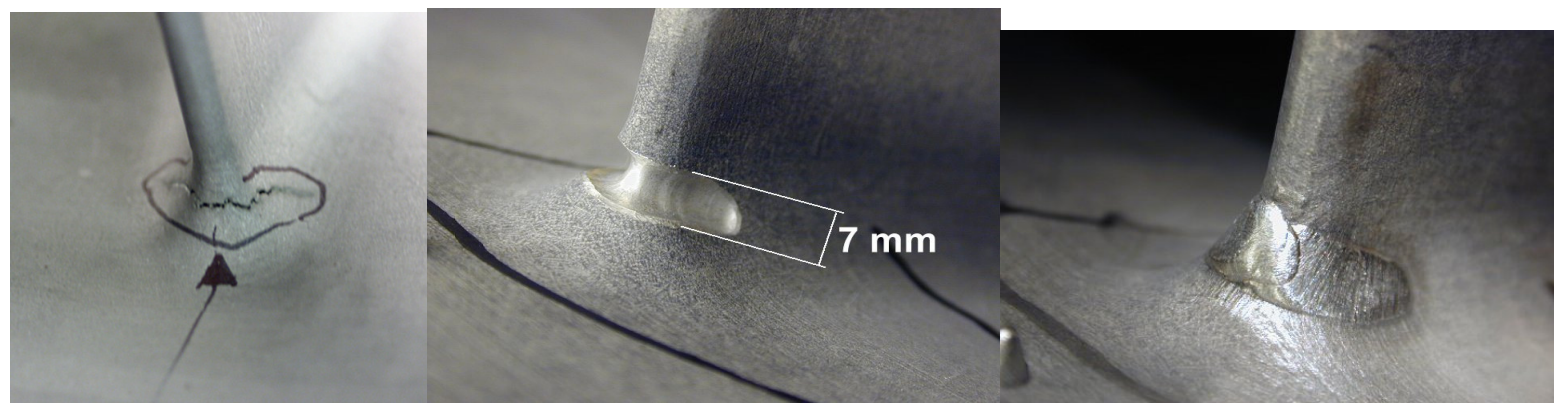

Figure 6. A "successful" (without new cracks) repair of a crack in cast Alloy 939 structure in the overaged condition. The crack is sealed by grinding the defect out and by using a soft filler material as $\mathrm{C} 263$ in the weld process to absorb induced weld stresses. 


\section{One Piece Casting - Assembly Parts - Mixed Cast Wrought Alloys}

As mentioned above, there are some instances when there are benefits splitting a structural component and later joining the parts by welding. Such a part may be called an assembly part. However, before the concept of the one piece casting for large structural parts arrived they were all of an assembly type where wrought and sheet materials were joined by welding. Today there are still parts that honor this heritage with success like the turbine exhaust case (TEC) in Greek Ascoloy, shown in Figure 7. Here wrought parts are joined with sheet metal parts.

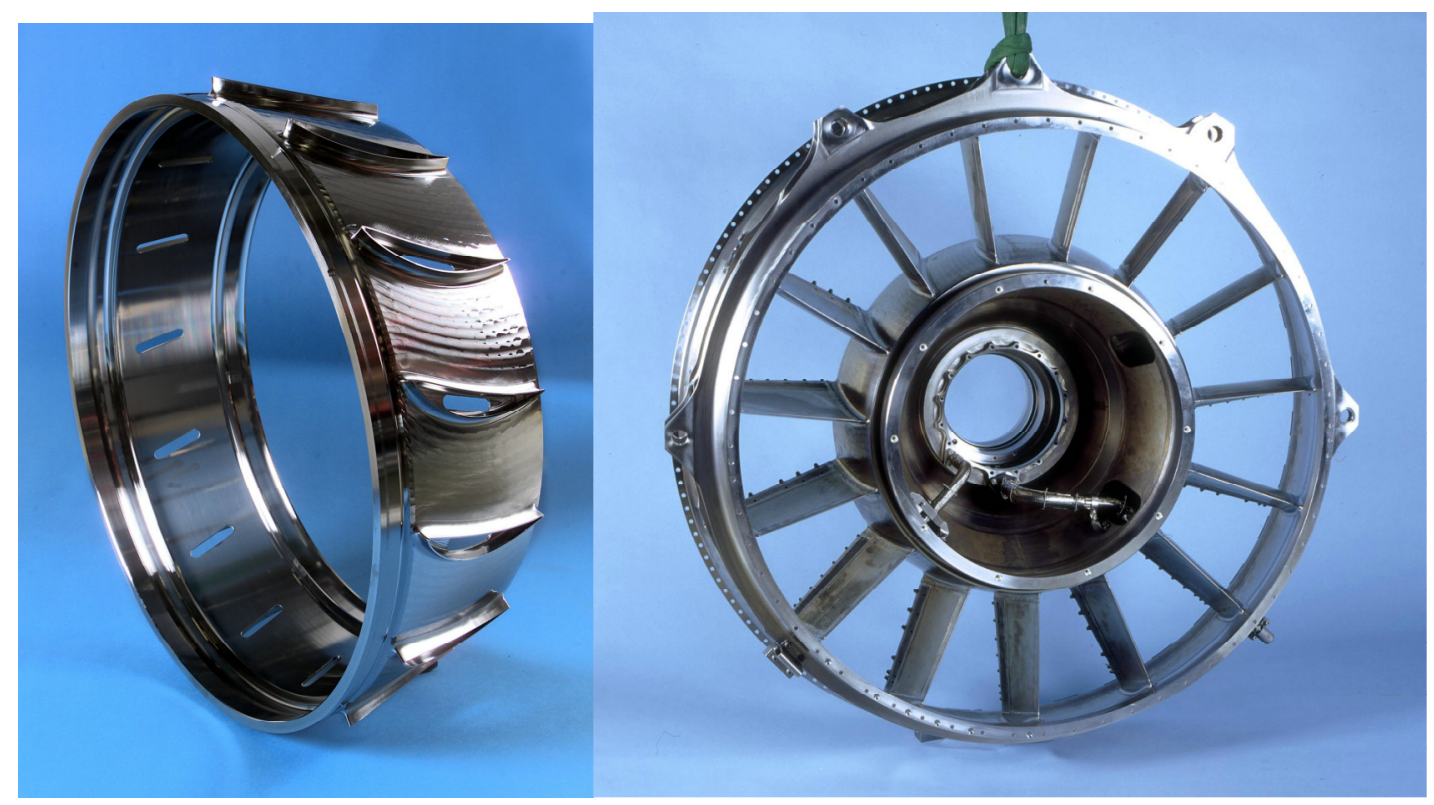

Figure 7. A "traditional" assembly part - a turbine exhaust case in Greek Ascoloy material. The milled wrought (ring rolled) inner and outer rings are joined by sheet metal struts.

Since wrought material is of considerably higher strength than the same alloy as cast, partly due to the finer grain size and partly due to its higher degree of homogeneity, it is possible to benefit from this fact in the design to minimize the weight of the component.

During recent years strong joint European development efforts, as shown in figure 8, have been made to "go back to the future" in terms of using the assembly approach for designing large structures not from necessity, as when the one piece high quality castings were not available, but as an innovative procedure to reduce weight by joining wrought, sheet and cast material. This paradigm shift in design has now been commercialized in the GEnx engine program for the turbine rear frame as shown in figure 8. At the same time it may be possible to avoid capital cost penalties specifically imposed on all necessary industrial equipments which are imperative for handling very large diameter castings. 


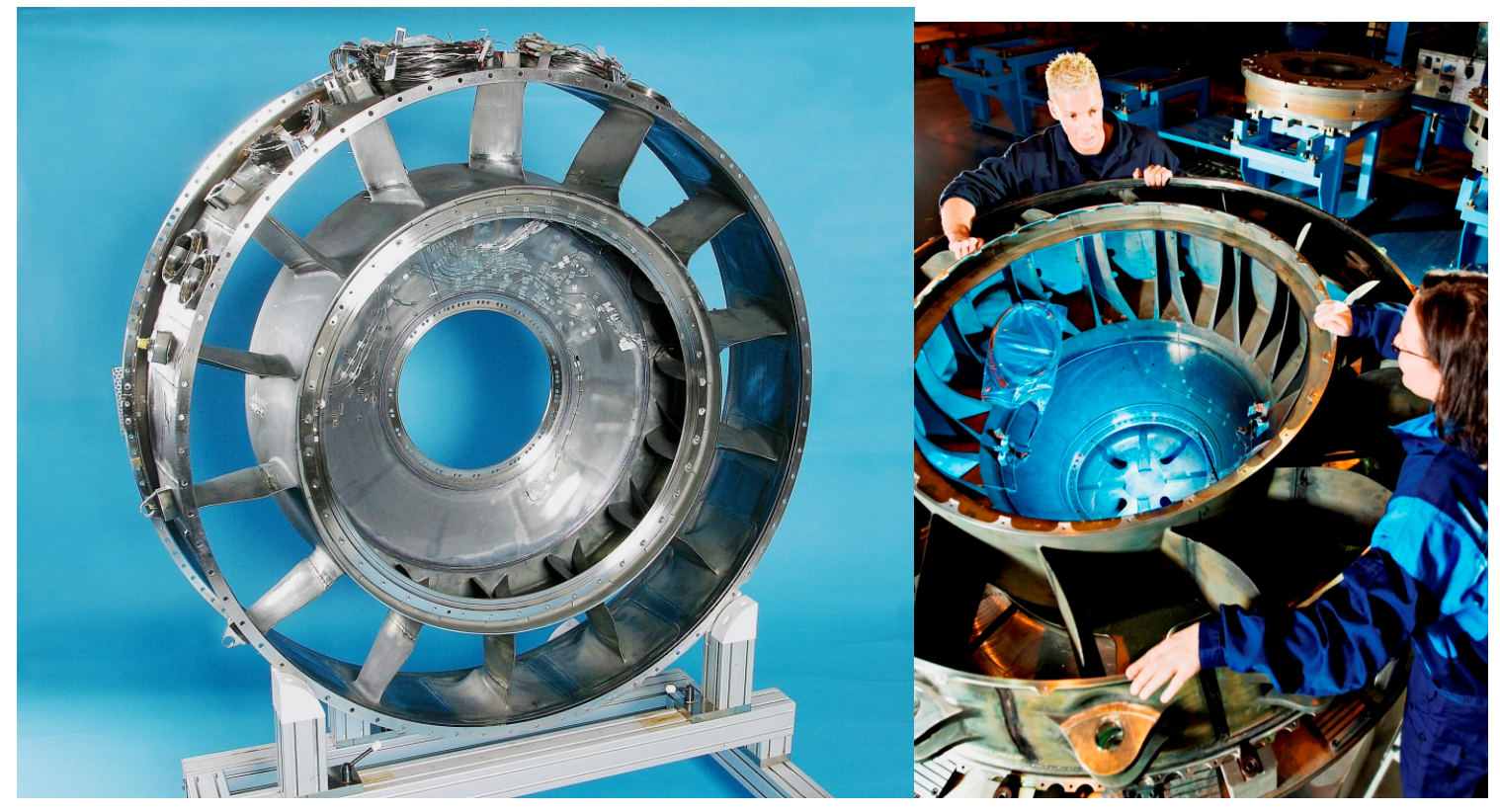

Figure 8 The "paradigmatic" return to the assembly concept for optimized structural parts. The European development program, ANTLE, to the left, where cast, wrought and sheet Alloy 718 material are joined by welding. The same concept commercialized in the GEnx program for the very large diameter turbine rear frame.

\section{Weldability}

From the very start of the jet engine era about 65 years ago, joining parts of high temperature resistant materials by welding was an integral part of the designs and specifically when turbine blades were joined to the disks ${ }^{\mathrm{ii}}$. The main concern at that time, as today, was how to avoid cracking. To circumvent the cracking problem the softest possible weld filler material available at that time was used; the type $316,18 \mathrm{Cr}-13 \mathrm{Ni}-3 \mathrm{Mo}$. An interesting fact is that we are using the same approach to avoid cracking today as discussed above with the development efforts on Alloy 939 for large structures where C263 was used as a filler material and where today the recently developed Haynes 282 is advocated ${ }^{\text {iv }}$. At the early times this was certainly an uphill battle due to the increasingly complex chemistries of the alloys which were necessary to meet the design demands on disks; primarily on strength at high temperatures. The welding battle was soon lost in favor of fir tree attachments the requirements on disks soon rendered the suitable alloys impossible to weld without cracking.

As always, design is an art of a more or less intelligent application of all available technologies but with an insatiable desire for more capable ones. Although, as mentioned earlier, while the chemical compositions of many of the present day materials were known early, the metallurgical industrial processes could not produce the high quality materials which are now possible through the vacuum technology. By the traditional, though rather new at that time, electric open hearth metallurgy it was very difficult to closely control the content of minor alloying elements. One of those elements was carbon and while it may confer beneficial high temperature strength properties through the carbides formed in grain boundaries it is one of the most detrimental element from the welding point of view. The reason is that carbon will form low melting carbide eutectic reactions during the solidification process. 
Towards the end of the solidification process, as the final liquid metal disappears, cohesion strength appears in the weld. However, at the same time, weld stresses develops due to thermal contraction. Due to the low melting point, the carbide eutectic (MC) is still liquid at this point and this liquid may attack and penetrate the freshly formed grain boundaries by the action of stresses across such boundaries combined with the wetting capacity of the eutectic melt. Such action of eutectic melts is the main cause for weld grain boundary cracking. Other elements than carbon forms equally or even more harmful eutectic melts. Sulfur is among the most detrimental elements since eutectics with as low melting point as $800{ }^{\circ} \mathrm{C}(\mathrm{NiS})$ may be present when weld stresses have reached considerably higher levels than at those temperatures around $1200{ }^{\circ} \mathrm{C}$ when $\mathrm{MC}$ eutectics solidifies and turned harmless from a grain boundary cracking point of view. By suppressing the sulfur content to lowest possible levels by elaborate vacuum metallurgy the weldability of superalloys can be considerably improved as e.g. in the CM 939Weldable alloy.

Weldability is a dubious term to use as a measure of the possibility to weld a specific alloy, since it is so difficult to define. Still, it is frequently used and often addressed with the reference to alloy composition where the content of aluminum and titanium are considered the main culprit for reducing the weldability due to their gamma prime hardening effect. Of course it is true that an alloy that hardens rapidly and to higher hardness levels will crack more easily than a leaner alloy, e.g. Waspaloy and Alloy 939. However, from the previous discussion on carbon and sulfur eutectics it should be clear that such an approach will be a gross oversimplification.

Weldability is often thought about in very specific terms, e.g. if it is possible to produce an assembly part like the GEnx turbine rear frame (Figure 8). As may be imagined numerous parameters are involved. The material, per se, is the most important one with the actual chemical composition and the state of heat treatment as secondary entities. The welding method chosen is though equally important; e.g. plasma, TIG or laser.

Cracking is the main stumble stone since any detectable weld crack must be ground out and repaired. Still, the main challenge with a huge complex part of this kind, as all welders with practical experience know, is to master all the overlapping distortions being built up in the weld sequence where geometry allowance limits must finally be met. This includes the additional geometry adjustments that will arrive when the weld stresses are relieved in the subsequent solution heat treatment applied when all welding operations are completed. New cracks may also arrive during this heat treatment which complicates the process as may be imagined.

It turns out that in order to be successful you need to master the complex sequence of welding in the specific part. Today this can be accomplished by efficient modeling and computer simulation $^{\text {vii }}$ of the whole set up as illustrated in Figure 9. 


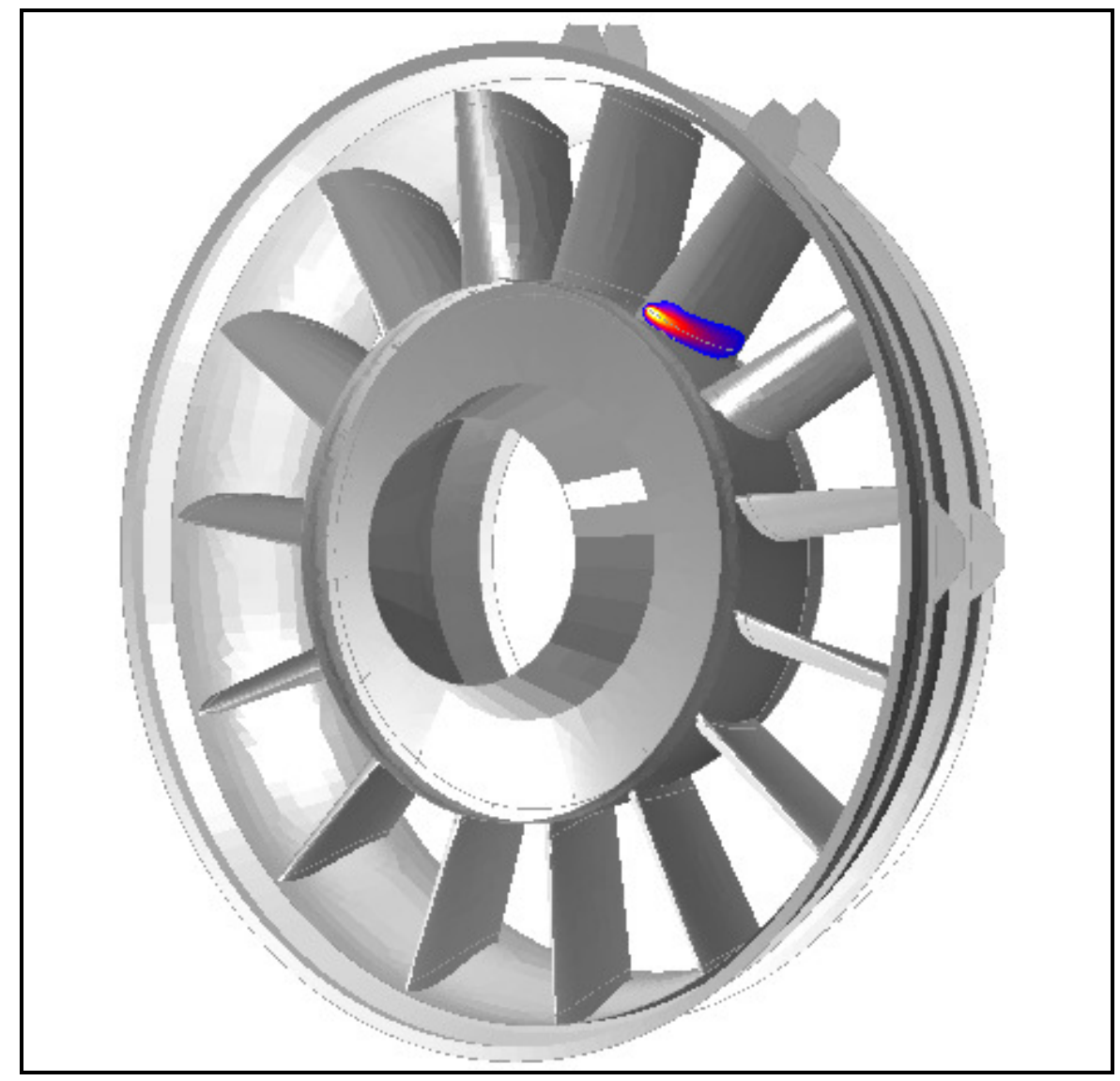

Figure 9. Efficient modeling and simulation of the welding process in sequence is a fundamental requirement for successful design and assembly manufacturing of large complex aircraft engine structures.

\section{Conclusions}

- Vacuum metallurgy is historically the single most important process development step that enabled the casting of large aircraft engine structures of high quality.

- Welding is the most critical process when higher temperature alloys are considered for one piece cast or assembly part structures.

- Higher temperature precipitation hardened alloys as alloy 939 may only be welded by using softer filler materials to alleviate weld stresses.

- The assembly concept for the largest engine structures allows for flexibility in design with a mixture of cast and wrought components for weight optimization.

- Efficient modeling and simulation of the weld process and weld sequence is necessary for successful control of the geometrical distortions in large weld assembly structural engine parts 
1. William R. Freeman, "Investment Casting”, Superalloys II, ed. Chester T. Sims, Norman S. Stoloff and William C. Hagel, (John Wiley and Sons, Inc. 1987), 411 - 439.

2. "Symposium on Materials for Gas Turbines", Forty-Ninth Annual Meeting, ASTM, 1946.

3. Chester T. Sims, "A History of Superalloy Metallurgy for Superalloy Metallurgists", Superalloys 1984, ed. M. Gell et al., (TMS 1984), 399-419.

4. Kenneth Harris, private communication with the author, March 2010.

5. Robert W. Hatala and John J. Schirra, "Developement of a Damage Tolerant Heat Treatment for Cast + HIP Incoloy 939”, Superalloys 1996, ed. R.D. Kissinger et al. (TMS, 1996), 137 - 143.

6. Göran Sjöberg et al., "Evaluation of the IN 939 Alloy for Large Aircraft Engine Structures", Superalloys 2004, ed. K.A. Green et al. (TMS, 2004), 441 - 450.

7. Lars-Erik Lindgren, Computational welding mechanics, (Woodhead Publishing Limited, 2007). 